\title{
Healthcare Workforce Increasing
}

\section{Physician Facts}

- Between 2008 and 2009, the national physician supply increased by $4.1 \%$, more than triple the rate of growth of the Canadian population as a whole (1.2\%).

- In 1979 , there were 150 physicians for every 100,000 Canadians; by 2009, that ratio had climbed to 201 per 100,000 .

- In 2009, Canadian faculties of medicine awarded a record number of medical degrees $(2,344)$, an increase of $34 \%$ over 2004 and $47 \%$ over 1999.

- In 2009, 295 physicians returned from abroad, compared with 203 who left Canada to work in other countries. This represents a net gain of 92 doctors - the highest gain in the last five years.

- Physicians' clinical payments totalled more than $\$ 17$ billion in 2008-2009, representing an increase of $9.6 \%$ over the previous year-the largest annual payment increase in 10 years.

- According to CIHI's 2010 National Health Expenditure Trends report, physician expenditures is the fastest-growing category of health spending.

- In 2009, the average age of a physician in Canada was 49.7, about the same as it was in 2008 (49.8).

- Almost three-quarters (72\%) of Canadian-educated medical graduates who set up practice in the province of their graduation were still there 10 years later. Retention of Canadianeducated medical graduates who set up practice in a province other than their place of graduation was much lower (44\%) and only slightly higher than that of international medical graduates (37\%).

\section{Nursing Facts}

- Between 2005 and 2009, Canada's regulated nursing workforce grew by nearly $9 \%$.

- Growth in the registered nurses (RNs) and licensed practical nurses (LPNs) workforces has exceeded the growth of the Canadian population.

- In 1992, there were $824 \mathrm{RNs}$ for every 100,000 Canadians, compared to 789 RNs for every 100,000 Canadians in 2009.

- Between 2005 and 2009, the average age of a Canadian nurse remained stable at 45 .

- In $2009,37 \%$ of RNs in the workforce had obtained a baccalaureate as their highest level of education in nursing, compared to $32 \%$ in 2005 .

- The number of LPNs increased by more than $18 \%$ between 2005 and 2009, outpacing growth in the Canadian population.

- The number of nurse practitioners (NPs) more than doubled between 2005 and 2009 and increased by $22 \%$ between 2008 and 2009 . NPs represent only $0.7 \%$ of the total registered nursing workforce. $\mathrm{HQ}$

\section{Sources}

Supply, Distribution and Migration of Canadian Physicians, 2009Canadian Institute for Health Information (CIHI).

https://secure.cihi.ca/estore/productFamily.htm?locale=en\&pf=PFC1 $567 \&$ lang=en\&media $=$

National Physician Database, 2008-2009 Data Release. Canadian Institute for Health Information (CIHI).

https://secure.cihi.ca/estore/productFamily.htm?locale=en\&pf=PFC1 566\&lang=en\&media $=$

Regulated Nurses: Canadian Trends, 2005-2009. Canadian Institute for Health Information (CIHI).

http://www.cihi.ca/CIHI-ext-portal/internet/EN/Products/products/ cihi000005

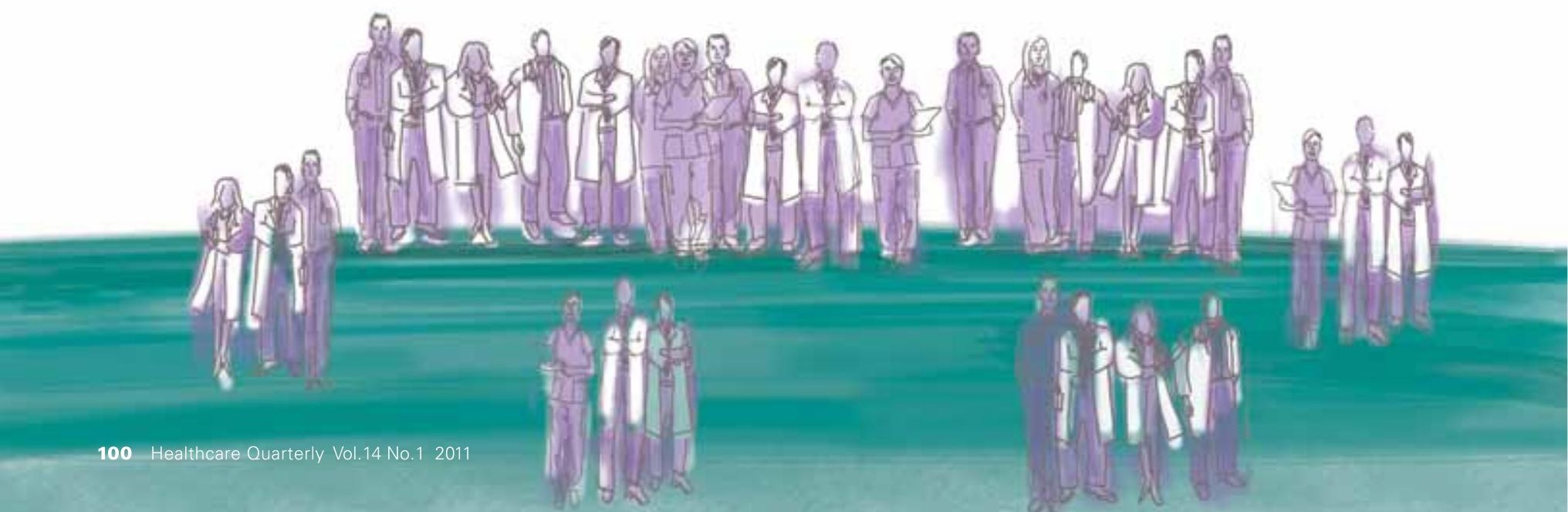




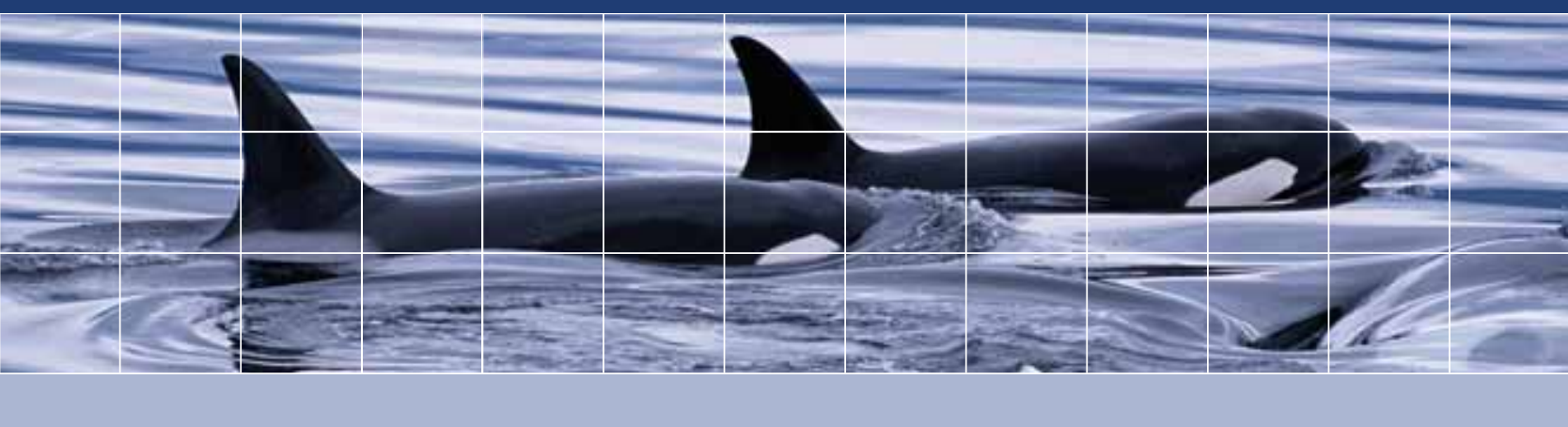

\section{Leaders in Health Care Executive Search}

Our mission is to ensure that each of our clients earns the highest return on their investment in leadership.

Ken Werker, Managing Partner, Vancouver
Under the leadership of James (Jim) Stonehouse, Managing Partner, the health care team at Odgers Berndtson has built the largest health care executive search practice in the country. With dedicated health care expertise in every Canadian office, the practice helps build leadership teams for public-sector health care providers, both institutional and community, private-sector providers, government agencies, not-for-profit organizations, health profession bodies, medical device, pharmaceutical and biotech firms.

Odgers Berndtson also has a robust physician search practice, having placed physicians in both leadership and pure clinical roles in institutional settings and private companies across Canada.

The firm also offers an interim management service in Canada to help our clients quickly fill critical executive roles on a temporary basis. Odgers Interim provides our valued clients with experienced talent on a flexible basis with the purpose of filling senior level positions for a temporary period of time or leading major projects and initiatives that require senior level expertise.

Odgers Berndtson is one of the leading international search firms with offices in 24 countries and 50 cities worldwide, and Canada's largest executive search firm with offices in Vancouver, Calgary, Toronto, Ottawa, Montreal and Halifax. Odgers Berndtson offers clients global reach with regional expertise. The firm specializes in recruiting executives and board members for a variety of organizations in the private, public and not-for-profit sectors.

Please feel free to contact any one of our health care team for additional information:

\section{Toronto Health Care Members:}

James Stonehouse, Managing Partner • Penny Mirams, Partner

Pam Colquhoun, Director, Physician Recruitment • Lorraine Manners, Engagement Manager Jane Matthews, President, Odgers Interim • Eric Beaudan, Leadership Assessment

National Health Care Expertise:

Mike Naufal, Managing Partner, Ottawa $•$ Ken Werker, Managing Partner, Vancouver Janet Soles, Managing Partner, Calgary • Genny Falconetto, Managing Partner, Montreal Maureen Millier, Managing Partner, Halifax

Toronto: 416-366-1990, Ottawa: 613-749-9909, Vancouver: 604-685-0261, Calgary: 403-410-6700, Montreal: 514-937-1000, Halifax: 902-491-7788

\section{healthcare@odgersberndtson.ca}

Executive Search / Interim Management / Leadership Assessment 